\title{
Enhanced efficiency for better wastewater sludge hydrolysis conversion through ultrasonic hydrolytic pretreatment
}

Dinh Duc Nguyen ${ }^{\mathrm{a}, \mathrm{b}}$, Yong Soo Yoon ${ }^{\mathrm{c}}$, Nhu Dung Nguyen ${ }^{\mathrm{c}}$, Quang Vu Bach ${ }^{\mathrm{a}}$, Xuan Thanh Buid $^{\text {, e }}$, Soon Woong Chang ${ }^{b}$, Hoang Sinh Le ${ }^{a}$, Wenshan Guo ${ }^{f}$, Huu Hao Ngo ${ }^{\text {a, f }}$

${ }^{a}$ Institute of Research and Development, Duy Tan University, Da Nang, Vietnam

${ }^{b}$ Department of Environmental Energy \& Engineering, Kyonggi University, 442-760, Korea

${ }^{c}$ Department of Chemical Engineering, Dankook University, Gyeonggi-do 448-701, Korea

${ }^{d}$ Faculty of Environment and Natural Resources, Ho Chi Minh City University of Technology, Ho Chi Minh City, Vietnam

${ }^{e}$ Dong Nai Technology University, Dong Nai, Vietnam

${ }^{f}$ Centre for Technology in Water and Wastewater, School of Civil and Environmental Engineering, University of Technology, Sydney, Australia

\section{Highlights}

- WAS test samples were disintegrated and homogenized into fine particle suspension.

- WAS ultrasonic solubilisation was significantly improved.

- Empirical equations are herein proposed on the basis of these experimental results.

- The effect of different sonicators for WAS disintegration was compared.

\begin{abstract}
The major requirements for accelerating the process of anaerobic digestion and energy production are breaking the structure of waste activated sludge (WAS), and transforming it into a soluble form suitable for biodegradation. This work investigated and analysed a novel bench-scale ultrasonic system for WAS disruption and hydrolysis using ultrasonic homogenization. Different commercial sonoreactors were used at low frequencies under a variety of operating conditions (intensity, density, power, sonication time, and total suspended solids) to evaluate the effects of the equipment on sludge hydrolysis and to generate new insights into the empirical models and mechanisms applicable to the real-world processing of wastewater sludge. A relationship was established between the operating parameters and the experimental data. Results indicated an increase in sonication time or ultrasonic intensity correlated with improved sludge hydrolysis rates, sludge temperature, and reduction rate of volatile solids $(33.51 \%)$. It also emerged that ultrasonication could effectively accelerate WAS hydrolysis to achieve disintegration within 5-10 min, depending on the ultrasonic intensity. This study also determined multiple alternative parameters to increase the efficiency of sludge treatment and organic matter reduction, and establish the practicality of applying ultrasonics to wastewater sludge pretreatment.
\end{abstract}


Keywords: ultrasonic pretreatment; sludge disruption; sludge hydrolysis; sludge reduction; sewage sludge

\section{Introduction}

Wastewater treatment processes using biological methods such as single or combination aerobic, anaerobic, and anoxic treatments have been core technologies for many several decades. Besides their advantages in terms of simplicity, ease of operation, economy, and effectiveness, these biological treatment processes also generate a large amount of biological sludge [1] and [2]. Processing and disposal of the sludge have become a heavy burden on environment and society and poses hazards if not handled appropriately. However, properly treated biosolids, especially WAS, represent very significant and valuable resources that can be recycled for many beneficial applications [3].

Many solutions and treatment technologies of WAS have been investigated and developed so far. For example, alkaline stabilisation, aerobic digestion, composting, thermal stabilisation, landfilling and ocean dumping are established methods of disposal, which have been implemented to varying degrees, and with mixed results. However, in recent years, given that more globally sustainable environmental management methods are required, anaerobic sludge treatment technologies are becoming more popular because they offer many advantages compared to other methods. This is especially the case through the use of sustainable applied bioenergy sources. However, if this technology is going to have widespread application, the acceleration, and control of anaerobic decomposition processes that effectively exploit bioenergy resources in this process represents a big challenge. Obtaining better efficiency from sludge hydrolysis or liquefaction is a key factor in creating a more homogenous and efficient WAS solution for the effective application of bioenergy technology. This technology, if properly understood and implemented, can significantly reduce sludge production, which must otherwise be treated as expansion or new construction of other expensive sludge treatment systems [4], [5], [6], [7], [8] and [9].

The rigid structure of aging sludge combined with the relative impermeability of microbial cell walls causes the amalgamation of biosolids in WAS, which creates a major problem. Such amalgamation prevents cell wall disruption and the release of inner cell products, which otherwise help to break down the overall mass. These problems hinder effective sludge digestion [10], and hence pretreatment is required to disrupt cell membranes, in order to completely lyse microbial cells in the solution. A well-performing ultrasonic system for WAS disruption and hydrolysis process will significantly improve the capacity of the system, and more important, may then reduce the capital cost. In addition, the system can easily be retrofitted to an existing sludge treatment system.

The sludge flocculates, with bacteria cells disintegrated by pressure, combined with free radicals (such as ${ }^{\circ} \mathrm{OH},{ }^{\cdot} \mathrm{H},{ }^{\circ} \mathrm{N}$, and ${ }^{\circ} \mathrm{O}$ ) and hydro-mechanical shear forces produced by ultrasonic cavitation at low frequencies, can break down quickly and effectively [4], [11], [12], [13], [14] and [15]. This results in the release of extracellular polymeric substances (EPS) and intracellular organic substances. This method can convert recalcitrant organic matter that is usually not readily biodegradable, into an abundant, readily biodegradable substrate that is available to increase the anaerobic community structure and 
enhance the activity of the bacterial consortium in the anaerobic digestion reactor. Furthermore, it increases in volatile solids degradation and biogas production.

In a nutshell, the sludge biological hydrolysis stage enhances important factors that may intervene to shorten the duration of anaerobic digestion (AD) and accelerate the process of biogas generation [4], [13] and [16]. This results in overall enhancement of the AD performance, thus representing an important milestone in the new design or upgrade of the capacity of existing anaerobic sludge treatment systems. At the present time, ultrasonic pretreatment of sludge is considered to be a highly effective, environmentally friendly [17], and cost-effective method compared with other techniques [18].

There have been many studies of sludge homogenised by ultrasound, with relatively interesting results [4], [13], [18], [19], [20] and [21]. However, they have only been proven on a small laboratory scale, and lack clear and consistently defined parameters in a form useful to engineers, consultants, designers, and scientists for larger scale, practical industrial applications $[22,23]$. Therefore, we seek to clarify some of the key factors and update this application, in order to optimise the efficiency of the treatment process, and generate higherquality effluent outputs. Instead, it will enable them to employ a sophisticated, predictable real-time, real-world, practical process to degrade various types of sludge.

In this study, we first investigated the influence of variables on system performance using different sonicators at low frequency for WAS disintegration under various operational conditions, and also discussed the specific energy of ultrasonic treatment. Secondly, we aimed to identify and establish the relationships and influences among the operating parameters (intensity, density, frequencies and sonication time) of ultrasonic and experimental data (sludge temperature, $\mathrm{pH}$, total suspended solids, total biodegradable material, etc.). Thirdly, new insights into the empirical models and mechanisms of sludge disintegration using different sonoreactors were explored. Finally, it attempted to comprehensively understand and clarify the influence of sonication on ultrasonic sludge disintegration.

\section{Methods}

\subsection{Characterizations of raw sludge}

Municipal wastewater consists of liquid and some biosolid wastes produced in homes, factories, commercial establishments, and from any point or non-point sources, such as agricultural runoff, urban pavements and surfaces, construction, etc. subsurface, surface, or storm water that enters the municipal wastewater collection systems. Depending on the type and extent of wastewater treatment, any of the materials that enter the municipal wastewater collection system may ultimately find their way into the sludge. Since influent is not constant in character from place to place or from time to time, the sludge resulting from its treatment varies highly in content ( Table 1). The sewage sludge was collected from five municipal wastewater treatment plants (WWTPs) in South Korea. Table 1 summarizes the sludge characteristics from each of the tested plants. 
Table 1. Characteristics of waste activated sludge.

\begin{tabular}{|c|c|c|c|c|c|c|c|c|}
\hline \multirow[t]{2}{*}{ No. } & \multirow[t]{2}{*}{ Parameters } & \multirow[t]{2}{*}{ Unit } & \multicolumn{6}{|c|}{ Waste activated sludge } \\
\hline & & & Min. & - & Max. & Aver. & \pm & Sdt. \\
\hline 1 & $\mathrm{pH}$ & - & 6.23 & - & 7.00 & 6.55 & \pm & 0.24 \\
\hline 2 & $\mathrm{TS}$ & $\mathrm{mg} / \mathrm{L}$ & 4124 & - & 11,993 & 6124.23 & \pm & 2636.87 \\
\hline 3 & TSS & $\mathrm{mg} / \mathrm{L}$ & 2500 & - & 11,672 & 5483.60 & \pm & 2923.50 \\
\hline 4 & VS & $\mathrm{mg} / \mathrm{L}$ & 3361 & - & 8804 & 4850.56 & \pm & $1,802.68$ \\
\hline 5 & VSS & $\mathrm{mg} / \mathrm{L}$ & 2100 & - & 8,439 & 4431.50 & \pm & $2,005.56$ \\
\hline 6 & Total COD & $\mathrm{mg} / \mathrm{L}$ & 4098 & - & 14,206 & 6666.26 & \pm & 3421.09 \\
\hline 7 & Soluble COD & $\mathrm{mg} / \mathrm{L}$ & 25 & - & 841 & 165.88 & \pm & 300.10 \\
\hline 8 & $\mathrm{~T}-\mathrm{N}$ & $\mathrm{mg} / \mathrm{L}$ & 230 & - & 590 & 370.00 & \pm & 116.19 \\
\hline 9 & $\mathrm{NH}_{4}-\mathrm{N}$ & $\mathrm{mg} / \mathrm{L}$ & 3 & - & 136 & 36.86 & \pm & 53.52 \\
\hline 10 & $\mathrm{~T}-\mathrm{P}$ & $\mathrm{mg} / \mathrm{L}$ & 401 & - & 1,437 & 653.43 & \pm & 353.72 \\
\hline 11 & $\mathrm{PO}_{4}-\mathrm{P}$ & $\mathrm{mg} / \mathrm{L}$ & 36 & - & 375 & 135.36 & \pm & 113.81 \\
\hline 12 & Alkalinity & $\mathrm{mgCaCO}_{3} / \mathrm{L}$ & 14 & - & 29 & 22.52 & \pm & 5.66 \\
\hline
\end{tabular}

\subsection{Ultrasonic system configuration and experimental set-up}

Fig. 1 shows a diagram that illustrates the ultrasound sonoreactor used in this study. The device was equipped, among other factors, with a power supply, a probe, and transducers. Two types of low-frequency ultrasound sonoreactors were used. The first sonoreactor was a horn-type ultrasound system (Fig. 1a) with three ultrasonic devices that, in turn, had the following specifications: UP-800 (800 W, $20 \mathrm{kHz}$, E-Chrom Tech Co., Ltd, Taiwan), VCX850 ( $850 \mathrm{~W}, 20 \mathrm{kHz}$, Germany), and VCX-700 (700 W, $20 \mathrm{kHz}$, Sonics \& Materials, Inc., USA). The second sonoreactor was a bath-type ultrasound system (Fig. 1b), MU-1500 (1500 W, $28 \mathrm{kHz}$, Mirae Ultrasonic Tech. Co., Korea) with a frequency of $28 \mathrm{kHz}$. The volume of the reactor was $20 \mathrm{~L}$, and it was equipped with 20 transducers arranged at the bottom and two sides of the reactor. All of the experiments were conducted in the $75 \%-85 \%$ amplitude range of the ultrasonic processors. 


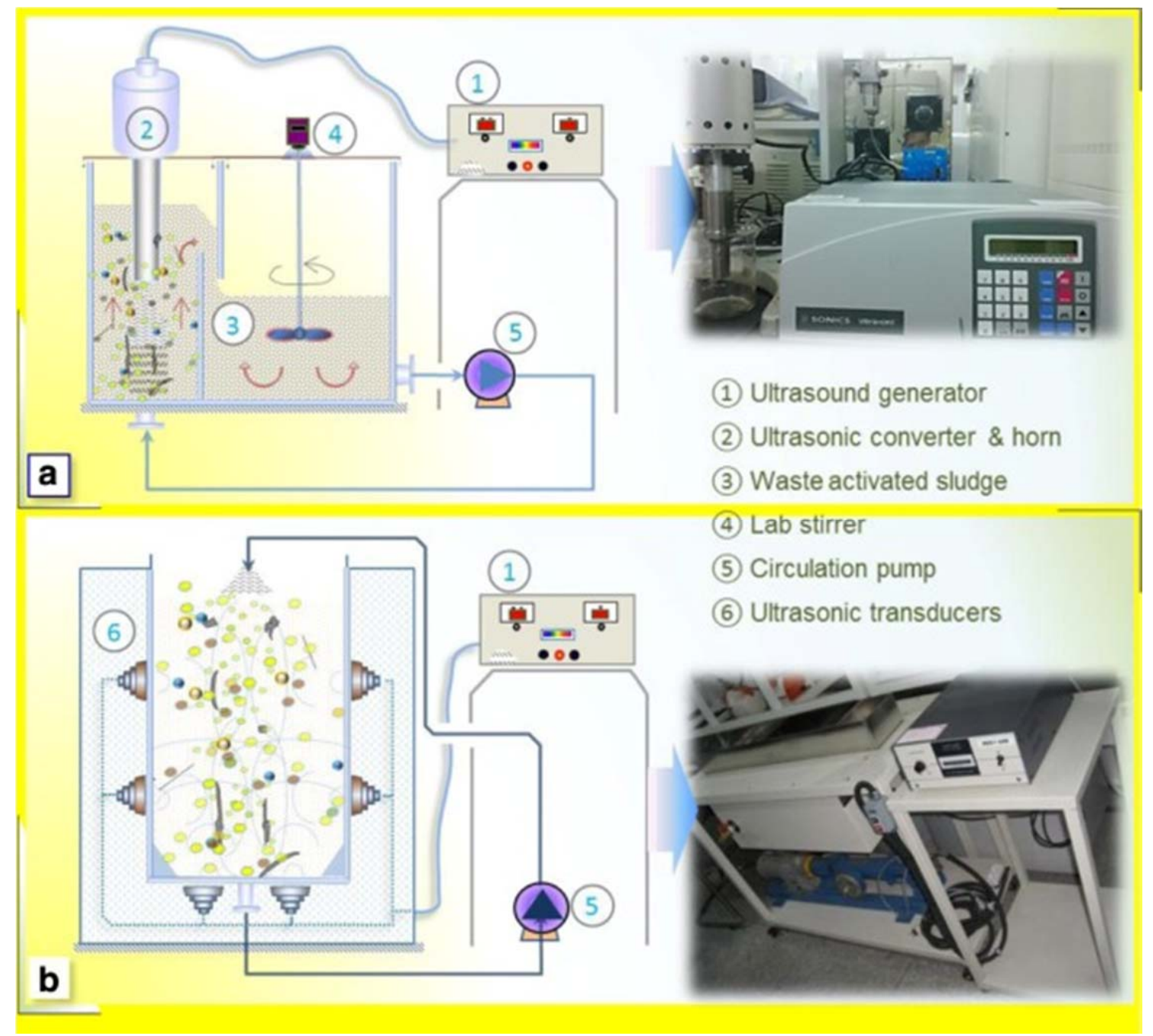

Fig. 1. Schematic diagram of the ultrasonic systems used in this study and photographs of (a) a horn-type sonoreactor, and (b) a bath-type sonoreactor.

\subsection{Sampling and analysis}

Sonicated sludge samples from the inline sonoreactor were collected during continuous operating mode over a desired period of time. All of the sample collections followed proper laboratory protocols for the sampling, preservation, and storage of specimens. The reagents used for testing the samples were analytical grade and were used without further purification

The quality of the sonicated sludge was determined by measuring the following: total dry solids (TS), total suspended solids (TSS), volatile solid (VS), total chemical oxygen demand $\left(\mathrm{TCOD}_{\mathrm{Cr}}\right)$, soluble $\mathrm{COD}_{\mathrm{Cr}}$, total nitrogen $(\mathrm{TN})$, ammonia nitrogen $\left(\mathrm{NH}_{4}{ }^{+}-\mathrm{N}\right)$, total phosphorus (TP), and phosphate $\left(\mathrm{PO}_{4}{ }^{3-}-\mathrm{P}\right)$ concentrations. These variables were all analysed according to standard methods [24]. Alkalinity concentration was determined by the titration method using $0.02 \mathrm{~N} \cdot \mathrm{H}_{2} \mathrm{SO}_{4}$ solution [25]. The $\mathrm{pH}$ values and temperature were measured with a CyberScan pH 510 m (Thermo Fisher Scientific Inc., USA). Mean particle size (MPS) and particle shapes in the sludge were measured using a Dynamic Imaging Particle Analysis System (Fluid Imaging Technologies Inc., US). 


\subsection{Data analysis}

The data obtained from experiment and modelling were analysed statistically using Origin 8.1 (OriginLab Corporation, USA) and Excel 2010 (Microsoft, USA), with a Solver add-in program. Statistical analysis of variance (ANOVA) was also conducted to assess the statistical significance of the model $(P$-value $<0.05)$.

\section{Results and discussions}

\subsection{Effects of ultrasonic irradiation on WAS floc structure and size}

Breaking the physical structure of activated sludge so that it can be transformed into a soluble form suitable for biodegradation, is the major determinant for accelerating the process of $\mathrm{AD}$ and energy production.

When an ultrasonic wave propagates and oscillates through solutions, it causes physical phenomena of repetitive compression and expansion, which then cause major formative transient cavitation, powerful micro jets, and micro-shock waves [26]. This energetic regime, in turn, becomes a key factor in the process of disrupting the sludge floc structure, especially the disintegration of biological cell walls, resulting in the release of cellular contents [27] and [28].

To verify the influence of ultrasound on disintegrating the structure of the activated sludge flocs, experiments were conducted on biological waste sludge $(7900 \mathrm{mg} / \mathrm{L})$. The ultrasonic device that was used for this purpose had the following features: $800 \mathrm{~W} ; 20 \mathrm{kHz}$; horn-type system with operating ultrasonic conditions of energy consumption per unit of the sonicated volume (ultrasonic density, D) of $0.905 \pm 0.004 \mathrm{~W} / \mathrm{mL}$; and energy consumption per unit of emitting area (ultrasonic intensity, I) of $339.028 \mathrm{~W} / \mathrm{cm}^{2}$, within the converter of $0.5 \mathrm{in}$, where it was changed to mechanical vibration.

The waste sludge samples were collected during ultrasonic irradiation at regular intervals, diluted with deionised water and continuously mixed at $60 \mathrm{rpm}$ for analysis of the mean particle size (MPS) and particle shapes in a moving fluid by a FlowCAM.

Fig. 2 shows the effects of ultrasonic waves, i.e., the breakup of sludge floc morphology (microbial structure of sludge) and size at different sonication times. The results show that the application of ultrasound is very effective in reducing the particle size of biomass, achieving a reduction to an average particle size of $>78.78 \%$ proportional to the length of time and intensity of ultrasonic irradiation exposure. This indicated that the sludge particles disintegrated and sludge particle size decreased, based on an inverse relationship between the sonication time and floc particle size. The application was highly effective, despite the fact that sludge floc observations before treatment revealed that the sludge flocs were dense and highly compact, composed of many sub-compartments with compact cores, cell clusters, bacterial colonies, protozoa, and filamentous bacteria, among other factors. Analysis of the effluent shows that the ultrasonic process significantly disintegrated the structural integrity of sludge flocs of all sizes. Floc pieces were reduced to as little as $<6.5 \mu \mathrm{m}$ under optimal treatment conditions, and were dissolved in the sludge slurry after 5-10 min of ultrasonic treatment with a low ultrasound frequency of $20 \mathrm{kHz}$. A longer ultrasound irradiation time was needed to reach this expected result, compared to previous studies [28] and [29]. 


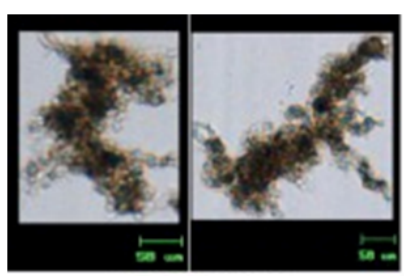

Initial WAS

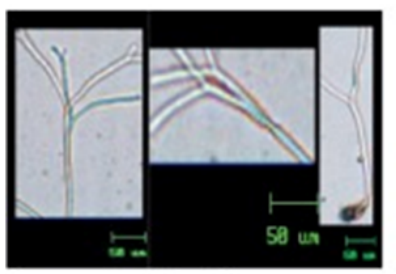

$20 \mathrm{~min}$

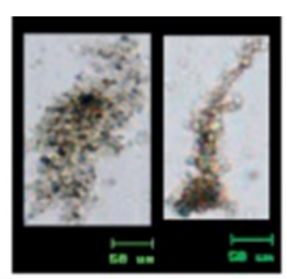

$5 \mathrm{~min}$

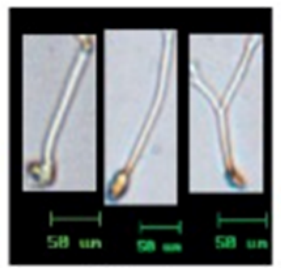

$25 \mathrm{~min}$

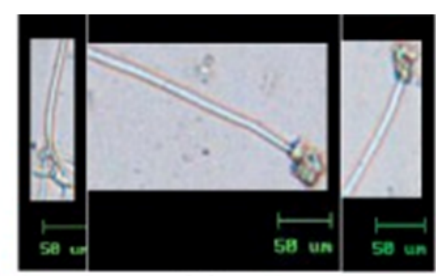

$10 \mathrm{~min}$

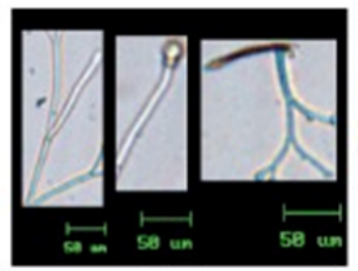

$30 \mathrm{~min}$

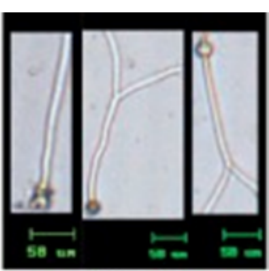

$15 \mathrm{~min}$

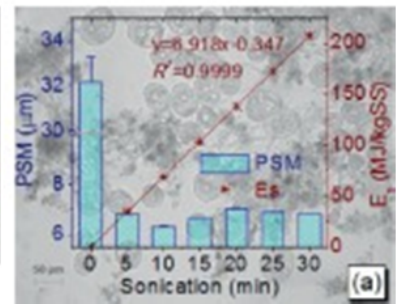

Fig. 2. Variations of the morphology of the activated sludge floc structure under different ultrasonic irradiation time using a $20 \mathrm{kHz}$ horn-type sonoreactor.

Interestingly, MPSs were rapidly reduced from 32.19 to $6.31 \mu \mathrm{m}$ over a treatment period of $10 \mathrm{~min}$. After the first ultrasound (Fig. 2a) and subsequent treatment cycles, the measurable effectiveness of size reduction tended to slow down and become almost insignificant. This outcome is ascribed to the fact that the absence of larger particles in the turbulent flow and micro-shock waves generated by cavitation in liquids led to larger particles being driven together at extremely high speeds, and induced effective particle disruption at the point of impact. However, it was observed that the remaining biological cells did not seem to be much affected by the ultrasound. This specifically refers to the stalks of Vorticella (Fig. 2).

This finding adds to the growing evidence that ultrasonic radiation can play a significant role in the process of disruption and micronization of biological sludge (structure, size, and status), and is of clear benefit to the AD process. However, the actual ultrasonic irradiation time achieved to disrupt the structural biology of cell walls depends on the density of biomass and sonication conditions [30]. The optimum ultrasonic pretreatment conditions achieved after 10 min ultrasonic irradiation treatment at a frequency of $20 \mathrm{kHz}$ and density of 0.905 $\mathrm{kW} / \mathrm{L}$, was more economical than the previously reported $3 \mathrm{~kW} / \mathrm{L}$ [31].

\subsection{Effects of ultrasonic irradiation on increasing the sludge temperature}

Controlling and using the optimal temperature in the sonoreactor are essential and contributory factors in energy losses, and are synonymous with the use of energy savings and efficiency. Moreover, temperature plays an important role in the AD process, not only to accelerate the growth rate and metabolism of anaerobic microorganisms, but also to support modification of the physicochemical properties and structure of the WAS components [32], [33] and [34].

Table 2 shows the different ultrasonic reactor settings of low-frequencies and sludge concentrations under which the serial experiments on the ultrasonic disintegration of WAS were performed. 
Table 2. Summary of the operating parameters and comparison of the performance-specific energy consumption of the sonoreactors.

\begin{tabular}{|c|c|c|c|c|c|c|c|c|c|}
\hline \multirow[t]{2}{*}{ Parameters } & \multirow[t]{2}{*}{ Units } & \multirow{2}{*}{$\begin{array}{l}\text { Operation } \\
\text { min }\end{array}$} & \multicolumn{2}{|l|}{$\mathbf{R 1}$} & \multirow{2}{*}{$\begin{array}{l}\text { R2 } \\
\text { run1 }\end{array}$} & \multicolumn{4}{|l|}{$\mathbf{R 3}$} \\
\hline & & & run1 & run2 & & run1 & run2 & run3 & run4 \\
\hline Rated power & $\mathrm{W}$ & & 700 & & 850 & 1500 & & & \\
\hline Frequency & $\mathrm{kHz}$ & & 20 & & 20 & 28 & & & \\
\hline Ultrasound intensity & $\mathrm{W} / \mathrm{cm}^{2}$ & & 138.15 & & 74.56 & 2.25 & & & \\
\hline Horn-tip diameter & $\mathrm{cm}$ & & 2.54 & & 3.81 & $60.00^{\circ}$ & & & \\
\hline $\begin{array}{l}\text { Volume of sonicated } \\
\text { sludge }\end{array}$ & $\mathrm{L}$ & & 1.7 & 1.7 & 10 & 20 & & & \\
\hline Sludge concentration & $\mathrm{mg} \mathrm{TSS} / \mathrm{L}$ & & 8600 & 7450 & 19580 & 6880 & 6860 & 6500 & 12100 \\
\hline pH of sludge & - & & 6.35 & 6.35 & 6.35 & 6.6 & 6.6 & 6.45 & 6.3 \\
\hline \multirow[t]{8}{*}{$\begin{array}{l}\text { Specific } \\
\text { consumption }\end{array}$} & $\mathrm{Wh} / \mathrm{L} /{ }^{\circ} \mathrm{C}$ & 30 & \multicolumn{2}{|c|}{$7.609-7.955$} & 1.642 & \multicolumn{3}{|c|}{$1.992-2.125$} & 2.277 \\
\hline & & 60 & \multicolumn{2}{|c|}{$7.475-7.644$} & 1.653 & \multicolumn{3}{|c|}{$2.125-2.198$} & 1.992 \\
\hline & $\mathrm{Wh} / \mathrm{gTSS} /{ }^{\circ} \mathrm{C}$ & 30 & \multicolumn{2}{|c|}{$0.925-1.021$} & 0.084 & \multicolumn{3}{|c|}{$0.306-0.31$} & 0.188 \\
\hline & & 60 & \multicolumn{2}{|c|}{$0.889-1.003$} & 0.084 & \multicolumn{3}{|c|}{$0.32-0.327$} & 0.165 \\
\hline & $\mathrm{Wh} / \mathrm{gsCOD}_{+}$ & 5 & \multicolumn{2}{|c|}{$27.778-53.03$} & 10.751 & \multicolumn{3}{|c|}{$19.611-26.067$} & 13.351 \\
\hline & & 20 & \multicolumn{2}{|c|}{$\begin{array}{l}40.936- \\
55.031\end{array}$} & 10.563 & \multicolumn{3}{|c|}{$21.465-24.709$} & 15.858 \\
\hline & & 30 & \multicolumn{2}{|c|}{$43.97-61.62$} & 11.525 & \multicolumn{3}{|c|}{$20.97-23.787$} & 17.137 \\
\hline & & 60 & \multicolumn{2}{|l|}{-} & - & \multicolumn{3}{|c|}{$20.698-21.321$} & 16.645 \\
\hline
\end{tabular}

* Transducer diameter.

Different operating conditions and ultrasonic devices were used for sludge pretreatment. The effects of ultrasonication as a function of irradiation time and temperature of WAS under these conditions are shown in Fig. 3. The results reveal that the variation of sludge temperature in the ultrasonicators is proportional to the duration of the ultrasound treatment, and follows an increasingly linear function in most runs, with a determinant coefficient of higher values of $R^{2}>0.96$ ( Fig. 3). 

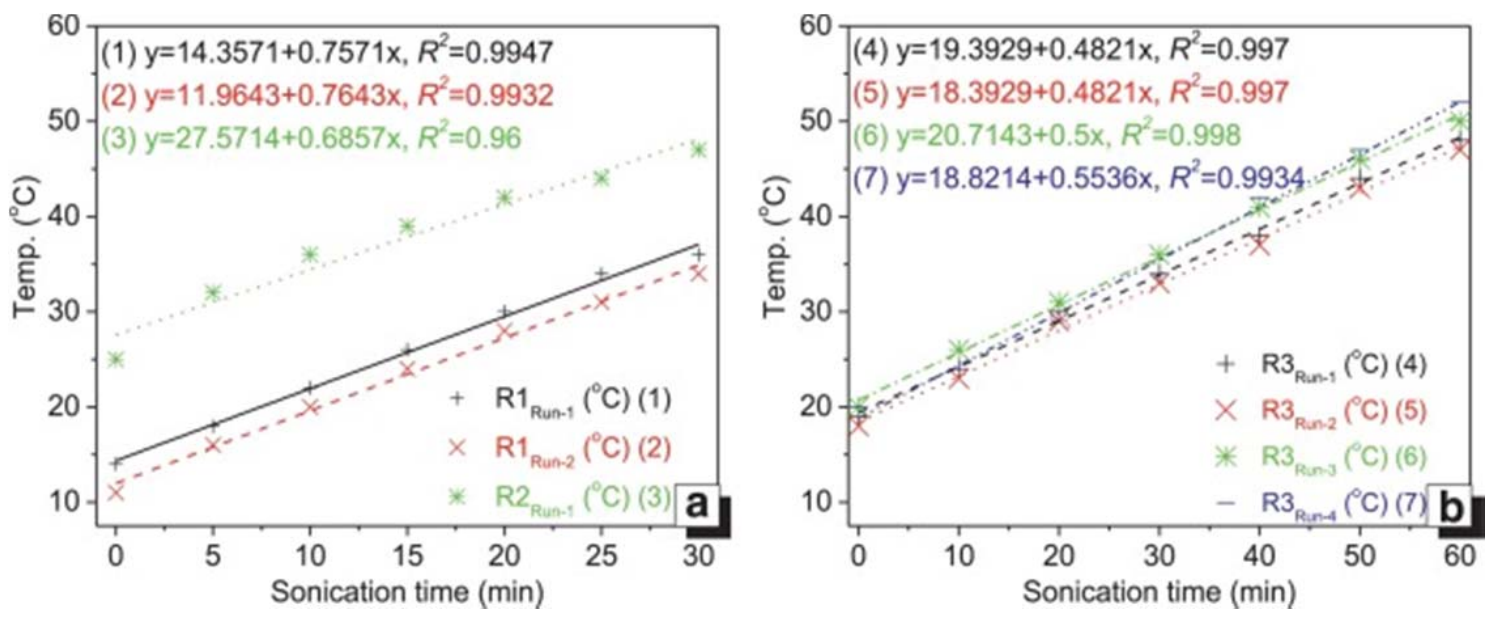

Fig. 3. Comparison of the variation in sludge temperature over ultrasound irradiation time under different operating conditions and sonoreactor.

Interestingly, the experimental results also revealed that, although there were differences in the energy needed to raise the temperature of $1 \mathrm{~L}$ of the WAS (or $1 \mathrm{~g}$ total suspended solids) by $1{ }^{\circ} \mathrm{C}\left({ }^{\circ} \mathrm{C}\right)$, and the initial sludge's temperature and concentrations (Table 1$)$, the trends and rate of temperature change in each sludge ultrasonicator in different running modes did not significantly differ during ultrasonic irradiation at low frequency (Fig. 4).
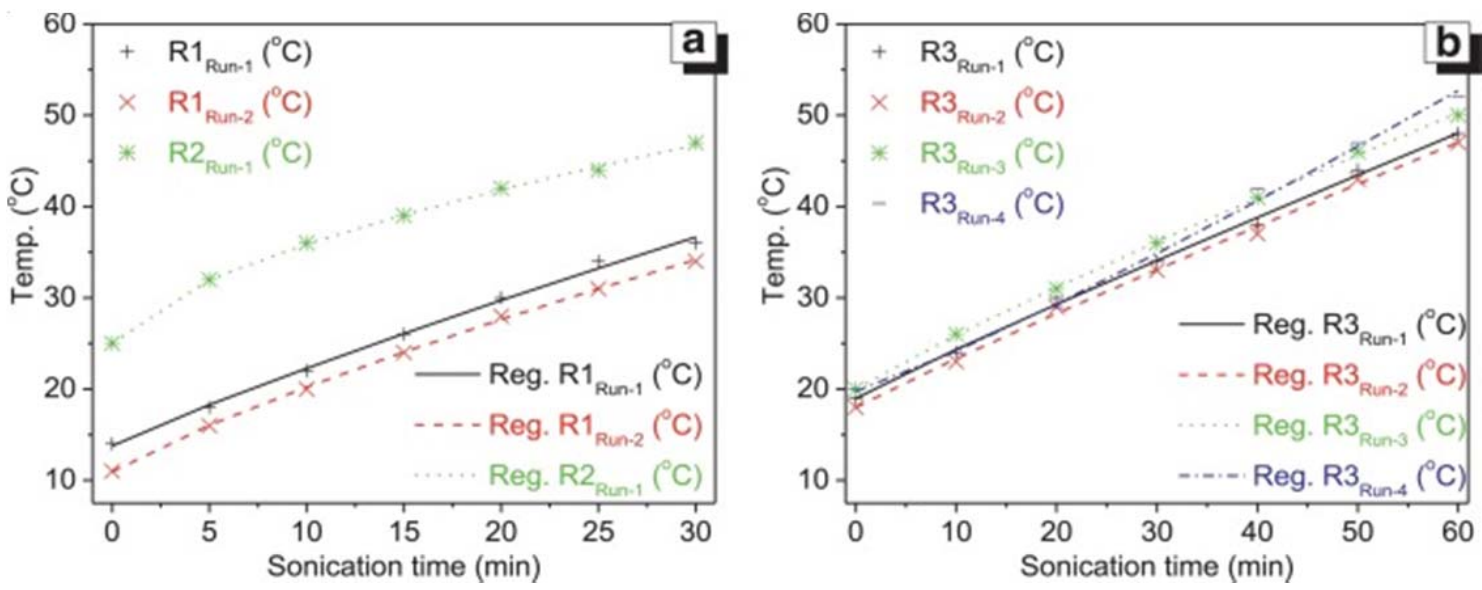

Fig. 4. Comparison of the experimental results (symbol shapes) with the linear regression analysis (lines). 
Table 3. Values of influence indices, constants and regression coefficients of the proposed modelling prediction of sludge temperatures under different runs.

\section{No. Experiment Model components and regression coefficients}

$\begin{array}{llllllllll}k 1 & \alpha & \beta & \gamma & \delta & C 1 & R^{2} & \text { SSR }\end{array}$

Sonoreactor 1 (R1)

$\begin{array}{llllllllll}1 & \text { R1-run1 } & 0.723 & -0.073 & 0.566 & -0.066 & 0.98 & 13.775 & 0.9969 & 1.2634 \\ 2 & \text { R1-run2 } & 0.429 & -0.122 & 0.543 & 0.118 & 0.848 & 10.934 & 0.9995 & 0.2177\end{array}$

Sonoreactor 2 (R2)

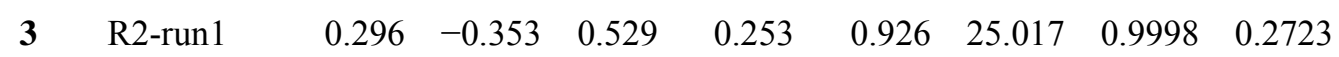

Sonoreactor 3 (R3)

$\begin{array}{llllllllll}\mathbf{4} & \text { R3-run1 } & 0.512 & -0.054 & 0.148 & 0.379 & 0.989 & 18.984 & 0.9986 & 1.5835 \\ \mathbf{5} & \text { R3-run2 } & 0.51 & -0.054 & 0.15 & 0.381 & 0.989 & 17.984 & 0.9984 & 1.5835 \\ \mathbf{6} & \text { R3-run3 } & 0.589 & -0.089 & 0.258 & 0.521 & 1.407 & 19.99 & 0.9998 & 0.2389 \\ \mathbf{7} & \text { R3-run4 } & 0.398 & 0.121 & -0.198 & -0.06 & 0.645 & 19.746 & 0.9977 & 3.4763\end{array}$

$C 1$, is adjustable constants; SSR is residual sum of squares; $R^{2}$ is determination coefficients.

When comparing the energy performance of the sonoreactors to raising the sludge temperature with different operating conditions at the same time, the energy consumption of the R3 and R2 ultrasound sonoreactors were in greater demand than the R1 ultrasound sonoreactor by 1.76 times and 1.21 times, respectively. It also emerged that the irradiating surface area (or diameter) of the ultrasonic transducer face or horn tip and the rated power seemed to play important roles. These results are also consistent with previous findings [21], [28] and [35].

Establishing empirical models are important in optimising the operating variables. With flexibility, one can easily adapt and adjust the device to real conditions, but still obtain the best results. Therefore, users have more options without considerations, but can still manage to achieve a good result as expected, by adjusting key parameters as a function of other interdependent parameters. In addition, to verify the accuracy of the test results, the system operation should support and increase the level of confidence in the work.

In order to establish the best ratios between each dependent and independent variable based on our experimental results, a model was developed to allow prediction of the raised sludge temperature-dependence versus parameters of ultrasonic treatment (ultrasonic density, ultrasonic intensity, irradiation time, amplitude, etc.) and WAS parameters ( $\mathrm{pH}$, solids concentration, etc.) based on the empirical formula of Wang et al.[21] (Eq. (1)). This enables one to determine trends and variations in temperature during an ultrasound treatment, and 
also aim for the best exposure time to ultrasound. By estimating the numerical parameters for this model, these studies can be determined to best-fit values, using least square method analyses.

$$
\frac{\mathrm{d}(\text { Temp. })}{\mathrm{d} t}=k \times[D]^{\alpha} \times[\mathrm{pH}]^{\beta} \times[I]^{\gamma} \times[C]^{\delta}
$$

The integration of the above equation can be abbreviated, and its abbreviated form can then be represented as Eq. (2):

$$
\mathrm{T}_{(\mathrm{t})}=\mathrm{k} \times \alpha[\mathrm{D}] \times \beta[\mathrm{pH}] \times \mathrm{y}[\mathrm{l}] \times \delta[\mathrm{C}] \times \mathrm{t}+\text { Constant }
$$

where, $T_{(t)}$ is the predicted value of the sonicated sludge temperature $\left({ }^{\circ} \mathrm{C}\right) ; k$ is the kinetics constant; $[D]$ is the ultrasonic density $(\mathrm{J} / \mathrm{mL}) ;[I]$ is the ultrasonic intensity $\left(\mathrm{W} / \mathrm{cm}^{2}\right) ;[C]$ is the percentage of total suspended solids inactivated sludge $(\%) ; \alpha$ is the influence index for ultrasonic density; $\beta$ is the influence index for the $\mathrm{pH}$ of WAS sludge; $\gamma$ is the influence index for ultrasonic intensity, and $\delta$ is the influence index for the sludge concentration.

Table 3 shows the calculated influence indices, constants and regression coefficients of the modelling predictions of sludge temperature under different runs. When determined by regression analysis, they represent reasonably high values for the coefficient of determination, $R^{2}$, for each run. This suggests that the proposed model is satisfactorily adjusted to the experimental data, and also suggests that Eq. (2) is appropriate for predicting the variation in the sludge temperature in an ultrasonicator over time. Fig. 3 shows the results (see legend for symbols and shapes) and regression analysis (lines) of the proposed model based on different sludge temperatures in the sonicator as a function of sonication time.

According to the evidence from the experimental results and regression analysis shown above, the ultrasonic process clearly affects the increasing temperature of the sample induced by ultrasound. The temperature increase in the sonicated sludge over time was due to the fact that: (i) the ultrasound device directly transformed electrical power into heat energy; and (ii) cavitation bubbles imploded due to collapse of the vacuum and release of energy as heat [36] and [37] and [38]. Additionally, in terms of increasing the sludge temperature, the bath-type sonoreactor (R3) was more energy-effective than horn-type sonoreactors (R1 and $\mathrm{R} 2$ ).

A higher temperature can be achieved, with a tendency for temperature variability over time. The sludge temperature, after a period of $18 \mathrm{~min}$, can achieve a level of maximum efficiency, making ultrasound possibly the most favourable AD process. It will not only achieve high methane production $[33,39]$ but also effectively remove up to $95 \%$ of COD. Furthermore, it can reduce greenhouse gas emissions, odours, and water contamination [32].

\subsection{Effects of ultrasonic irradiation on the release of organic matters}

WAS usually contains highly organic components, and as such, is readily biodegradable. This process can be highly accelerated, under optimal conditions. Thus WAS is an ideal candidate for the AD process. However, the increasing dissolution rate in these processes, especially at the biological hydrolysis stage, has been recognised as an important rate-limiting step in the $\mathrm{AD}$ process [4] and [40]. Consequently, these serial experiments were executed in order to explore and evaluate the ultrasound-assisted optimal solubilisation of WAS, so as to increase the dissolution rate of sCOD. 
During the ultrasonic radiation of WAS, variable sCODs using lower frequencies under different running modes were obtained (Fig. 5). The results suggest that through ultrasound pretreatment, the sCOD production from WAS increased linearly and substantially. In all the sonicators, the increases correlated well with a variety of ultrasonic irradiation levels through first order linear equations $\left(R^{2}>0.975\right)$. However, the rate depended on the characteristics of the sludge and ultrasonic device, for example, sludge concentration, active cavitation zone, specific energy, exposure time, etc. The $\mathrm{pH}$ value of the WAS did not change by much during ultrasonication and remained in the range of 6.3-6.6.

The results are shown in Fig. 5a illustrate that over $30 \mathrm{~min}$ of sonication, the sCOD concentration in the reactor R1 increased in both runs (R1-run1 and R1-run2). After 20 min of sonication, the averaged SCOD concentration of reactor R1 rose by up to 72 times with an initial averaged SCOD concentration of $35 \mathrm{mg} / \mathrm{L}$, and this trend continued. In contrast, after 20 min of sonication, the sCOD concentration in reactor R2 increased only eightfold, which corresponded to the sCOD concentration increase from $320 \mathrm{mg} / \mathrm{L}$ to $2600 \mathrm{mg} / \mathrm{L}$, and then levelled off at steady state after that . This difference could be attributed to (i) the active cavitation zone of reactor R2 was almost double that of reactor R1, and (ii) the quantity of sludge flocs exposed to ultrasonic cavitation of reactor R2 was double that of reactor R1. However, in terms of absolute values, the SCOD after $20 \mathrm{~min}$ of sonication of both reactors (R1 and R2) were similar, at $2890 \mathrm{mg} / \mathrm{L}$ (R1-run1), $2150 \mathrm{mg} / \mathrm{L}$ (R1-run2) and $2600 \mathrm{mg} / \mathrm{L}$ (R2-run1).

Ultrasonic disintegrations of WAS using a bath-type ultrasonic reactor with a low frequency of $28 \mathrm{kHz}$, and different sludge concentrations were carried out in four runs (Table 2). Fig. 5b shows that the variation in SCOD was quantified to determine the change in sonicated WAS within the bath-type ultrasonic reactor.

Similar to the results for the sludge temperature changes in other experiments, it was found that the longer the period of ultrasonic irradiation, the higher the SCOD release that could be achieved within the tested data range. Fig. 5 shows a near-perfect correlation of the same data. Equally important, the results also showed that the sludge concentration had a stronger impact than the ultrasonic intensity, expressed visually by the slopes of the first order linear equation (Fig. 5). When the sludge concentration was higher, the probability of sludge flocs encountering a jet-stream created by the cavitation was higher, and consequently, more extracellular polymeric substances (EPS) and intercellular organics were released. This contributed to the generation of higher SCOD and reduced the particle size of the treated WAS. Moreover, when compared in terms of the specific energy needed to increase sCOD by 1\% (Table 2), it emerged that R2 was more energy efficient than R1 (Table 3).

The results clearly elucidated the beneficial effects obtained by using ultrasound in sludge disintegration, e.g., reducing the particle size, breaking particles down into lower molecular weight, and solubilising intracellular material. Thus, enhancing the rate-limiting hydrolysis in the next step would significantly improve the anaerobic biodegradation process [40] and [41].

The relationship between incremental increases of sCOD in sonicated sludge, and major operating variables of ultrasonic devices and WAS during ultrasonic irradiation, was also studied, and parameters were established in a model. This was done in order to identify the most suitable indicator to assess how well the ultrasonic system performed. The empirical formula as proposed by Wang et al. [21] was modified and applied, as follows: 


$$
\frac{\mathrm{d}(\mathrm{sCOD})}{\mathrm{d} t}=k \times[D]^{\varepsilon} \times[\mathrm{pH}]^{\zeta} \times[I]^{\eta} \times[C]^{\theta} \times[T]^{\varphi}
$$

The integration of the above equation can be written as Eq. (4):

$$
\operatorname{sCOD}_{(t)}=k \times[D]^{\varepsilon} \times[\mathrm{pH}]^{\zeta} \times[I]^{\eta} \times[C]^{\theta} \times[T]^{\varphi} \times t+\text { Constant }
$$

where, $\operatorname{sCOD}(t)$ is the predicted value of soluble $\operatorname{COD}$ of sonicated sludge $(\mathrm{mg} / \mathrm{L}) ; k$ is the kinetics constant; $[D]$ is the ultrasonic density $(\mathrm{J} / \mathrm{mL}) ;[I]$ is the ultrasonic intensity $\left(\mathrm{W} / \mathrm{cm}^{2}\right)$; $[T]$ is the sludge temperature during ultrasonic treatment $\left({ }^{\circ} \mathrm{C}\right) ;[C]$ is the percentage of total suspended solids in activated sludge (\%); $\varepsilon$ is the influence index for ultrasonic density; $\zeta$ is the influence index for the $\mathrm{pH}$ of WAS sludge; $\eta$ is the influence index for ultrasonic intensity, and $\theta$ is the influence index for sludge concentration ( Fig. 5).
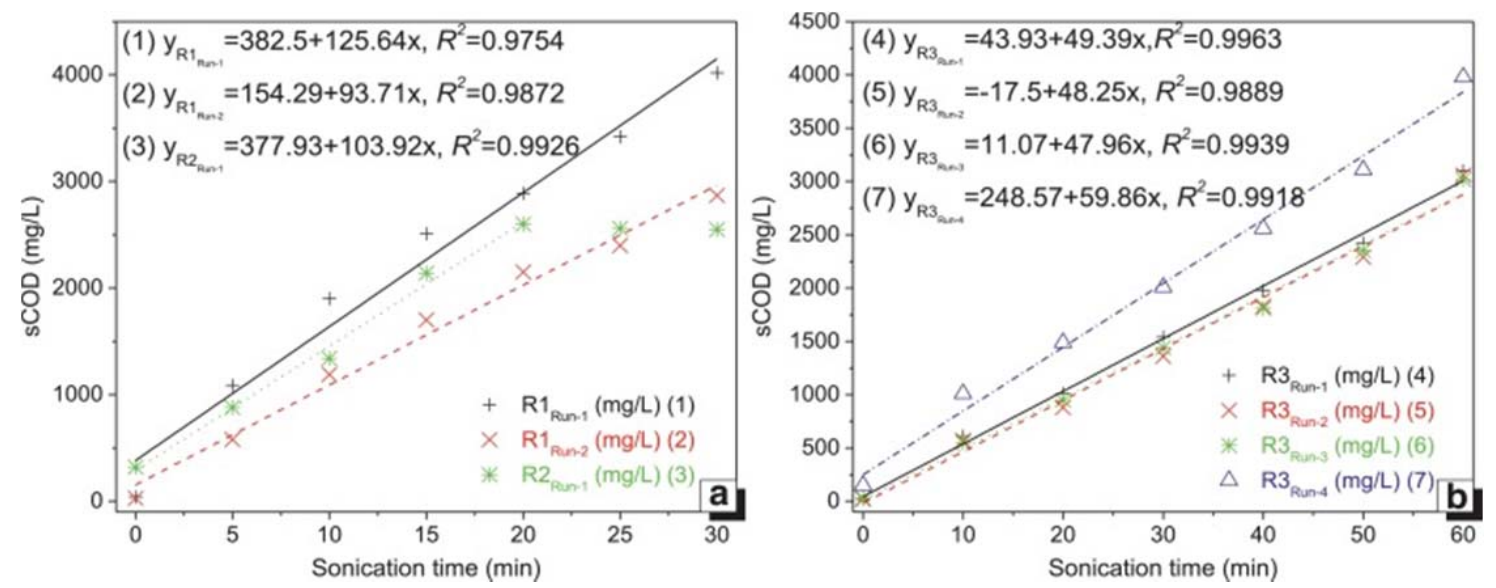

Fig. 5. Comparison of the variation of sludge sCOD over ultrasound irradiation time under different ultrasonic devices (sonoreactors).

Raising the temperature during the process of ultrasonic disintegration has several benefits, including increasing the solubility of the organic compounds; enhanced biological and chemical reaction rates; and enhanced pathogens death rate [32], [33] and [34]. Therefore, this empirical formula should include temperature increments. The parameters of empirical formulae were identified and computed using the least squares method, and Table 4 shows the corresponding actual experimental data obtained with predetermined values of sludge. 
Table 4. Values of influence indexes, constants and regression coefficients of modelling the prediction of sludge sCOD under different runs.

No. Experiment Model components and regression coefficients

$\begin{array}{llllllllll}k 2 & \varepsilon & \zeta & \eta & \theta & l & C 2 & R^{2} & \text { SSR }\end{array}$

\section{Sonoreactor 1 (R1)}

\begin{tabular}{|c|c|c|c|c|c|c|c|c|c|c|}
\hline $\mathrm{R} 1$ & run1 & 2.443 & 0.215 & 2.617 & 0.33 & -4.715 & -1.313 & 54.542 & 0.999 & 11886 \\
\hline 2 & run2 & 1.201 & 0.043 & 1.173 & 0.827 & 0.906 & -0.541 & 2.037 & 0.9966 & 21085 \\
\hline
\end{tabular}

Sonoreactor 2 (R2)

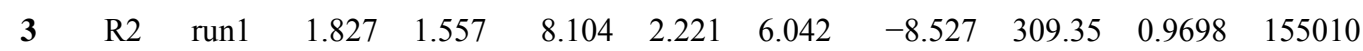

\section{Sonoreactor 3 (R3)}

\begin{tabular}{|c|c|c|c|c|c|c|c|c|c|c|c|}
\hline 4 & R3 & run1 & 1.05 & -0.319 & 1.151 & 1.2 & 0.812 & 0.683 & 1.104 & 0.9968 & 21943 \\
\hline 5 & & run2 & 0.843 & -0.509 & 0.672 & 0.867 & 1.05 & 1.317 & 1.143 & 0.9943 & 37322 \\
\hline 6 & & run3 & 0.874 & -0.657 & 0.429 & 0.717 & 1.163 & 1.656 & 1.18 & 0.997 & 19604 \\
\hline 7 & & run4 & 1.073 & -0.737 & 1.056 & 1.136 & 1.053 & 1.202 & 1.218 & 0.9913 & 88352 \\
\hline
\end{tabular}

$\mathrm{C} 2$, adjustable constants; SSR, residual sum of squares; $R^{2}$, determination coefficients.

Fig. 6 shows the experimental results (symbol shapes) and regression analysis (lines) of the proposed model on the variable of sCOD release using a sonicator as a function of sonication time under different experimental conditions.
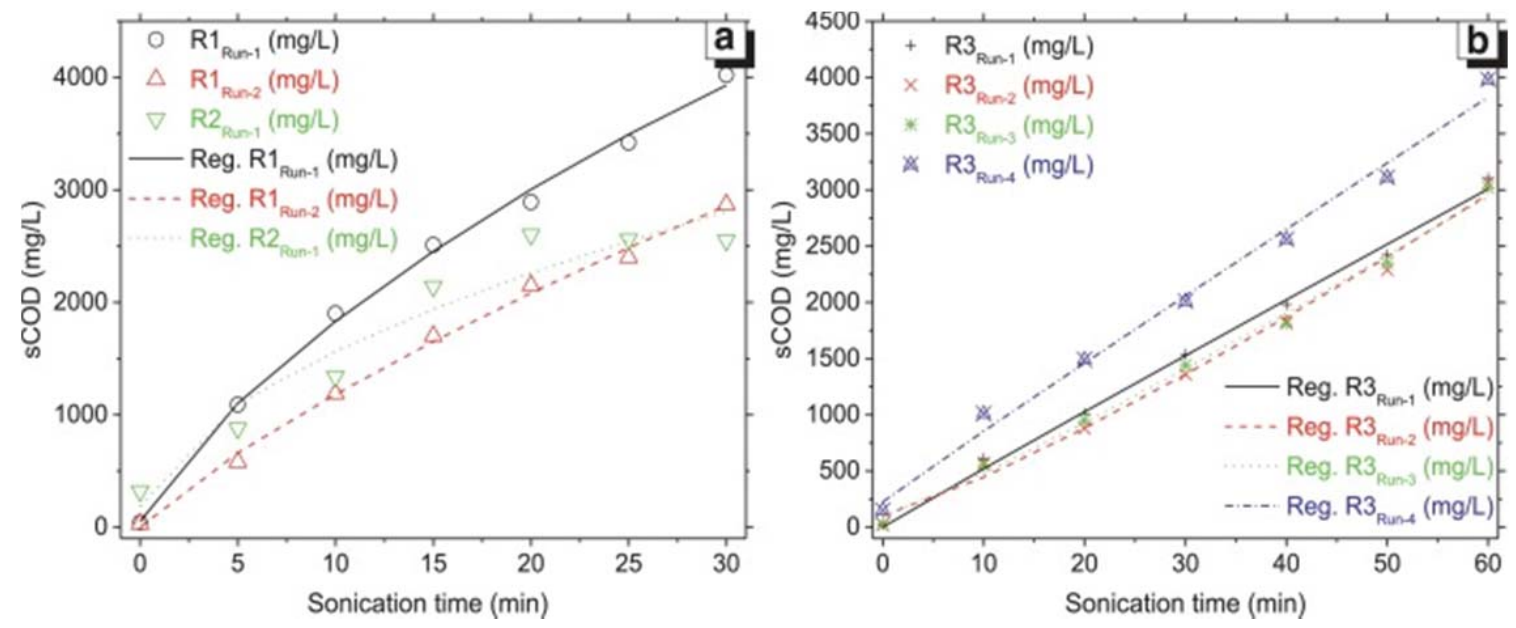

Fig. 6. Experimental results (symbol shapes) and regression analysis (lines) by the proposed model on the variable of sCOD in sonicators as a function of sonication time.

According to the regression results, the high value of the coefficient of determination $\left(R^{2}>\right.$ 0.987 ) indicates a very good fit of the results with the proposed empirical formula, and approximately $98 \%$ of the response variations could be explained by the regression model. This also indicates that a good correlation exists between the proposed model and 
experimental results for both reactors. These results reaffirm that the empirical formulae of Eqs. (1) and (3) with operating variables can be used to predict the variations in sludge temperatures and sCOD release in ultrasound systems during the sonication process under different operating conditions. The evidence from the experiments mentioned above and the regression analysis suggest that, when the ultrasonic irradiation time increased, this resulted in an increase in the temperature and SCOD of sonicated WAS.

\subsection{Comparison between horn-type and bath-type sonoreactors}

Table 2 summarises the results obtained for both horn-type and bath-type reactors. The results showed that in terms of increasing the sludge temperature, the bath-type sonoreactor is more energy-effective than the horn-type. In other words, transforming the irradiation power setting of the ultrasound reactor into heat resulted in the violent collapse of the cavities [42] and [43].

With reference to increasing SCOD, when the sludge TSS concentration was lower than 9122 $\mathrm{mg} / \mathrm{L}$, the sludge viscosity versus sludge concentration changed [44], and when compared to the horn-type reactor, the specific energy consumption of the bath-type reactor was about $38.60 \%-47.69 \%$ of the specific energy consumption. However, when the sludge TSS concentration was higher than $9122 \mathrm{mg} / \mathrm{L}$, the specific energy consumption of the bath-type reactor was 1.487 times greater than those of the horn-type reactor.

Consequently, with a sludge concentration of less than $9122 \mathrm{mg} / \mathrm{L}$, the obtained results matched the data obtained by Majumdar et al., [45], which reported that with the same conditions of sludge that had undergone sonication, the cavitation effectiveness of the bathtype reactor could be more than the horn-type reactor, ranging from 3.5- to 3.8-fold. The hydromechanical shear forces produced by ultrasonic cavitation constitute the main disintegration mechanism of ultrasound [4] and [46]. The degree of cell disintegration increases proportionally to the logarithm of the bubble radius, and the last is inversely proportional to the ultrasound frequency [4]. Therefore when the TSS concentration of the sludge is higher than $9122 \mathrm{mg} / \mathrm{L}$, the sludge density plays an important role.

According to the evidence from the experimental data this study collected, when the TSS concentration of sludge is less than $9.1 \mathrm{~g} / \mathrm{L}$, the bath-type ultrasonic reactor is the preferred device to use for sludge disintegration; and when the TSS concentration of sludge is higher than $9.1 \mathrm{~g} / \mathrm{L}$, the horn-type will be more energy efficient. The main drawback of horn-type reactors is that due to trapped fibres in the sludge, erosion of the sonotrode and clogging of the reactor may occur. These problems were not experienced with the bath-type reactor.

In terms of the exposure time to ultrasonic cavitation necessary to achieve the highest threshold of soluble COD that is acceptable, the ideal amount of time required in a horn-type reactor varied from 5 to $20 \mathrm{~min}$. However, in a bath-type reactor, in order to reach the same level of efficiency, the run-time varies from 25 to $40 \mathrm{~min}$ of sonication, depending on operating conditions. Although this efficiency can be increased, to generate a higher level of soluble COD, the energy consumption required would result in a subsequent increase in operating costs. Consequently, when scaling up sonoreactors, the trade-off between the capital and operational costs is recommended. In turn, this will lead to significant savings in energy consumption and better efficiency in WAS treatment plants. 


\section{Conclusions}

These results provide a more reliable solution and robust option for wastewater sludge pretreatment. Ultrasound has emerged as a viable technique that can improve sewage sludge $\mathrm{AD}$, in terms of reduction of the volume of waste produced; increased sludge stabilisation; and enhancement of biogas generation. This can be achieved by more effectively disintegrating the sludge, and changing its inherent mechanical characteristics.

The ultrasonic pretreatment of WAS shortened the hydrolysis phase and also increased the hydrolysis rate, thereby significantly increasing the effectiveness of $\mathrm{AD}$ of sludge, and greatly reducing sludge in the waste stream. In addition, it helped maintain steady-state conditions in the digester, and reduced shock loadings for the next treatment stage. This improvement in efficiency can result in a shorter overall waste treatment time.

The correlation and degree of influence between the operating parameters and experimental data were established, thus indicating that sonication time, ultrasonic density, ultrasonic intensity, and solid concentrations affect the activated sludge solubilisation and the sonicated sludge temperature. With the empirical equations developed in this study, designers and engineers can design a control algorithm to automatically adjust operating parameters corresponding to the total solids concentration fed to the digester, in order to achieve the desired results.

\section{Acknowledgements}

This work was supported in part by grants from the Korea Ministry of Environment, as a "Global Top Project" (Project No.: 2016002210003) and as Advanced Technology Program for Environmental Industry (Project No.: 2016000140004). The authors are very grateful for research collaborations between Kyonggi University, South Korea and the University of Technology, Sydney, and also acknowledge the help of Dr. Phu Nguyen in analysing the morphology of the activated sludge flocs.

\section{References}

[1] Naddeo V, Belgiorno V, Landi M, Zarra T, Napoli RMA. Effect of sonolysis on waste activated sludge solubilisation and anaerobic biodegradability. Desalination 2009;249:762-7.

[2] Hung Y-T, Wang LK, Shammas NK. Handbook of environment and waste management: air and water pollution control. World Scientific; 2012.

[3] Girovich MJ. Biosolids treatment and management: processes for beneficial use. CRC Press; 1996.

[4] Tiehm A, Nickel K, Zellhorn M, Neis U. Ultrasonic waste activated sludge disintegration for improving anaerobic stabilization. Water Res 20 01;35:20 03-9.

[5] Zhang J, Lv C, Tong J, Liu J, Liu J, Yu D, Wang Y, Chen M, Wei Y. Optimization and microbial community analysis of anaerobic co-digestion of food waste and sewage sludge based on microwave pretreatment. Bioresour Technol 2016;200:253-61.

[6] Toreci I, Kennedy KJ, Droste RL. Evaluation of continuous mesophilic anaerobic sludge digestion after high temperature microwave pretreatment. Water Res 2009;43:1273-84. 
[7] Ge H, Jensen PD, Batstone DJ. Temperature phased anaerobic digestion increases apparent hydrolysis rate for waste activated sludge. Water Res 2011;45:1597-606.

[8] Schievano A, Tenca A, Lonati S, Manzini E, Adani F. Can two-stage instead of one-stage anaerobic digestion really increase energy recovery from biomass. Appl Energy 2014;124:335-42.

[9] Leite WRM, Gottardo M, Pavan P, BelliFilho P, Bolzonella D.Performance and energy aspects of single and two phase thermophilic anaerobic digestion of waste activated sludge. Renewable Energy 2016;86:1324-31.

[10] Pavlostathis SG, Gossett JM. A kinetic model for anaerobic digestion of biolog- ical sludge. Biotechnol Bioeng 1986;28:1519-30.

[11] Wang Q, Kuninobu M, Kakimoto K, Hiroaki I, Kato Y. Upgrading of anaerobic digestion of waste activated sludge by ultrasonic pretreatment. Bioresour Technol 1999;68:309-13.

[12] Zennaki Z, Zaid A, Lamini H, Aubineau M, Boulif M. Methane fermentation of cattle manure: effects of hydraulic retention time, temperature and substrate concentration. Al Awamia; 1996. p. 15-31.

[13] Show K-Y, Mao T, Lee D-J. Optimisation of sludge disruption by sonication. Water Res 2007;41:4741-7.

[14] Gong C, Jiang J, Li D, Tian S. Ultrasonic application to boost hydroxyl radical formation during Fenton oxidation and release organic matter from sludge. Sci Rep 2015;5:11419. doi: 10.1038/srep11419.

[15] Sivakumar M, Pandit AB. Ultrasound enhanced degradation of Rhodamine B: optimization with power density. Ultrason Sonochem 2001;8:233-40.

[16] Pilli S, Bhunia P, Yan S, LeBlanc RJ, Tyagi RD, Surampalli RY. Ultrasonic pretreatment of sludge: A review. Ultrason Sonochem 2011;18:1-18.

[17] Feng X, Lei H, Deng J, Yu Q, Li H. Physical and chemical characteristics of waste activated sludge treated ultrasonically. Chem Eng Process: Process Intensif 2009;48:187-94.

[18] Zou S, Wang H, Wang X, Zhou S, Li X, Feng Y. Application of experimental design techniques in the optimization of the ultrasonic pretreatment time and enhancement of methane production in anaerobic co-digestion. Appl Energy 2016;179:191-202.

[19] Chiu Y-C, Chang C-N, Lin J-G, Huang S-J. Alkaline and ultrasonic pretreatment of sludge before anaerobic digestion. Water Sci Technol 1997;36:155-62.

[20] Le NT, Julcour-Lebigue C, Barthe L, Delmas H. Optimisation of sludge pre- treatment by low frequency sonication under pressure. J Environ Manage 2016;165:206-12.

[21] Wang F, Wang Y, Ji M. Mechanisms and kinetics models for ultrasonic waste activated sludge disintegration. J Hazard Mater 2005;123:145-50.

[22] Zou S, Wang X, Chen Y, Wan H, Feng Y. Enhancement of biogas production in anaerobic co-digestion by ultrasonic pretreatment. Energy Convers Manage 2016;112:22635 . 
[23] Gogate PR, Sivakumar M, Pandit AB. Destruction of Rhodamine B using novel sonochemical reactor with capacity of 7.5 1. Sep Purif Technol 2004;34:13-24.

[24] A. APHA, WEF. Standard methods for the examination of water and wastewater. Washington, DC, USA: American Public Health Association; 1998. p. 20.

[25] Lahav O, Loewenthal R. Measurement of VFA in anaerobic digestion: the five-point titration method revisited, 26. SA, Pretoria: WATER; 200 0. p. 389-92.

[26] Manickam S, Zainal Abidin Nb, Parthasarathy S, Alzorqi I, Ng EH, Tiong TJ, et al. Role of $\mathrm{H} 2 \mathrm{O} 2$ in the fluctuating patterns of COD (chemical oxygen demand) during the treatment of palm oil mill effluent (POME) using pilot scale triple frequency ultrasound cavitation reactor. Ultrason Sonochem 2014;21:1519-26.

[27] Mason TJ, Tiehm A. Advances in sonochemistry. Ultrasound in environmental protection, Vol. 6. Elsevier; 2001. [28] Chu CP, Chang B-V, Liao GS, Jean DS, Lee DJ. Observations on changes in ultrasonically treated waste-activated sludge. Water Res 2001;35:1038-46.

[29] Gong C, Jiang J, Li Da. Ultrasound coupled with Fenton oxidation pre-treatment of sludge to release organic carbon, nitrogen and phosphorus. Sci Total Environ 2015;532:495500 .

[30] Chen D, Sharma SK, Mudhoo A. Handbook on applications of ultrasound: sonochemistry for sustainability. CRC Press; 2011.

[31] Yu G-H, He P-J, Shao L-M, Zhu Y-S. Extracellular proteins, polysaccharides and enzymes impact on sludge aerobic digestion after ultrasonic pretreatment. Water Res 2008;42:1925-34.

[32] Arikan OA, Mulbry W, Lansing S. Effect of temperature on methane production from field-scale anaerobic digesters treating dairy manure. Waste Manage 2015;43:108-13.

[33] Bouallagui H, Haouari O, Touhami Y, Ben Cheikh R, Marouani L, Hamdi M. Effect of temperature on the performance of an anaerobic tubular reactor treating fruit and vegetable waste. Process Biochem 2004;39:2143-8.

[34] Wu-Haan W. Evaluation of ultrasonic pretreatment on anaerobic digestion of biomass for methane production. ProQuest; 2008.

[35] Mahulkar AV, Riedel C, Gogate PR, Neis U, Pandit AB. Effect of dissolved gas on efficacy of sonochemical reactors for microbial cell disruption: experimental and numerical analysis. Ultrason Sonochem 2009;16:635-43.

[36] Suslick KS, Didenko Y, Fang MM, Hyeon T, Kolbeck KJ, McNamara WB, et al. Acoustic cavitation and its chemical consequences. Philos Trans R Soc London A: Math, Phys Eng Sci 1999;357:335-53.

[37] Sivakumar M, Tatake PA, Pandit AB. Kinetics of $p$-nitrophenol degradation: effect of reaction conditions and cavitational parameters for a multiple frequency system. Chem Eng $\mathrm{J}$ 2002;85:327-38.

[38] Nguyen DD, Ngo HH, Yoon YS, Chang SW, Bui HH. A new approach involving a multi transducer ultrasonic system for cleaning turbine engines' oil filters under practical conditions. Ultrasonics 2016;71:256-63. 
[39] Hawkes FR, Rosser BL, Hawkes DL, Statham M. Mesophilic anaerobic digestion of cattle slurry after passage through a mechanical separator: factors affecting gas yield. Agric Wastes 1984;10:241-56.

[40] Appels L, Baeyens J, Degrève J, Dewil R. Principles and potential of the anaerobic digestion of waste-activated sludge. Progress Energy Combust Sci 2008;34:755-81.

[41] Kavitha S, Jessin Brindha GM, Sally Gloriana A, Rajashankar K, Yeom IT, Rajesh Banu J. Enhancement of aerobic biodegradability potential of municipal waste activated sludge by ultrasonic aided bacterial disintegration. Bioresour Technol 2016;200:161-9.

[42] Li J, Sanderson RD, Jacobs EP. Ultrasonic cleaning of nylon microfiltration membranes fouled by Kraft paper mill effluent. J Membr Sci 2002;205:247-57.

[43] Fuchs FJ. Ultrasonic cleaning, fundamental theory and application. NASA; 1995. NASA Conference Publication p. 369.

[44] Kang C-W, Hua J, Lou J, Liu W, Jordan E. Bridging the gap between membrane bioreactor (MBR) pilot and plant studies. J Membr Sci 2008;325:861-71.

[45] Majumdar S, Kumar PS, Pandit AB. Effect of liquid-phase properties on ultrasound intensity and cavitational activity. Ultrason Sonochem 1998;5:113-18.

[46] Sivakumar M, Pandit AB. Wastewater treatment: a novel energy efficient hydrodynamic cavitational technique. Ultrason Sonochem 2002;9:123-31. 